\title{
Typologie des plantations villageoises de palmier à huile (Elaeis guineensis Jacq.) dans le département du Plateau au Bénin
}

\author{
H. AHOLOUKPE ${ }^{1,2,3^{*}}$, V. P. VISSOH ${ }^{2}$, G. AMADJI ${ }^{2}$, P. DELEPORTE ${ }^{3}$, B. DUBOS ${ }^{4}$, \\ L. NODICHAO ${ }^{1}$, R. GLELE KAKAÏ ${ }^{2}$, J.L. CHOTTE ${ }^{5}$ et D. BLAVET ${ }^{5}$ \\ ${ }^{I}$ Centre de Recherches Agricoles Plantes Pérennes, Institut National des Recherches Agricoles du Bénin, \\ BP 01 Pobè, Benin. \\ ${ }^{2}$ Faculté des Sciences Agronomiques, Université d'Abomey-Calavi, BP 526 FSA/UAC, Cotonou, Benin. \\ ${ }^{3}$ CIRAD, UMR Eco\&Sols, Place Viala, 34060 Montpellier Cedex 2, France. \\ ${ }^{4}$ CIRAD, UPR Systèmes de pérennes, F-34398 Montpellier, France. \\ ${ }^{5}$ IRD, UMR Eco\&Sols, Place Viala, 34060 Montpellier Cedex 2, France. \\ *Auteur correspondant, E-mail. aholoukpeherve@yahoo.fr; Tel : (229) 96720404.
}

\section{RESUME}

Une typologie des palmeraies villageoises du département du Plateau au sud-est du Bénin a été établie à travers : i) une étude cartographique de la couverture pédologique et d'occupation des sols, ii) des entretiens semi-structurés en assemblée générale avec des groupes de producteurs choisis de façon aléatoire dans chaque commune, iii) des entretiens semi-structurés individuels avec quatre vingt dix producteurs dont les palmeraies sont installées sur les terres de barre et étudiées par une analyse factorielle des correspondances multiples. Les terres de barre sont les sols les plus plantés avec le palmier à huile et Adja-Ouèrè et Sakété constituent les communes de grosse production. Les palmeraies du département présentent $\mathrm{i}$ ) des caractéristiques très peu variables : la densité de plantation, le précédent cultural, les pratiques d'association des cultures vivrières et d'utilisation des engrais et ii) des caractéristiques variables et spécifiques : la restitution des sous-produits de transformation et le recyclage des feuilles d'élagage des palmiers. Parmi les cinq modalités de gestion des feuilles d'élagage identifiées, l'exportation des feuilles est une pratique dominante dans le département. Sur les terres de barre, on retrouve quatre types de palmeraies qui se différencient par la superficie, les pratiques culturales et l'âge des palmeraies.

(C) 2013 International Formulae Group. All rights reserved.

Mots clés: Palmeraies villageoises, sols, sud-Bénin, pratiques culturales, typologie, palmier à huile.

\section{INTRODUCTION}

En Afrique tropicale, l'huile de palme occupe une position prépondérante dans la production agricole, les échanges et la consommation de corps gras. Au Bénin, le palmier à huile joue un rôle économique important et est l'oléagineux le plus productif.
Dans les années 1990, l'huile de palme représentait au Bénin plus de 50\% de la production en huile végétale (Djégui et Daniel, 1996) et couvrait près de la moitié de la demande nationale annuelle en corps gras, soit 6 à $9 \mathrm{~kg} / \mathrm{habitant} / \mathrm{an}$ (Adjé et Adjadi, 2001; Fournier et al., 2001). 
En raison de l'importance du palmier à huile dans l'économie et la sécurité alimentaire des familles rurales (Adjadi, 2008 ; MAEP, 2009), on assiste de nos jours à une forte expansion des palmeraies villagoises au Bénin. Ces palmeraies sont qualifiées de «villageoises» par opposition aux palmeraies industrielles (Rafflegeau, 2008). L'organisation de la filière du palmier à huile sélectionné au Bénin a connu de grandes étapes historiques. Le programme de plantation à grande échelle a été lancé par l'Etat colonial dans les années 1950, puis renforcé après l'indépendance (1960) par l'Etat béninois (Fournier et al., 2002). Mais ce programme a connu par la suite des difficultés qui ont entrainé une baisse de la production d'huile de palme pour deux raisons : la baisse de la pluviométrie et la fluctuation des cours mondiaux des corps gras caractérisé par la concurrence des pays producteurs des zones écologiquement plus favorables (Fournier et al., 2002). L'Etat béninois a donc procédé à une réorganisation de la filière en installant de grandes plantations de taille supérieure à 500 ha, gérées par des coopératives d'aménagement rural (CAR) et alimentant des unités industrielles de traitement des régimes de palme (Adjadi, 2008). A partir des années 1990, un projet financé par l'Union Européenne et l'Etat béninois a contribué à une large diffusion en milieu villageois du matériel végétal sélectionné par la recherche agronomique. Ce projet s'est appuyé sur les structures de recherche [station de Pobè : Centre de Recherches Agricoles Plantes Pérennes (CRA-PP)] et de développement agricoles [Centre d'Action Régionale pour le Développement Rural (CARDER)] dont les rôles fondamentaux ont été la fourniture de matériel végétal sélectionné et la formation des producteurs (Adjé et Adjadi, 2001). Dès lors, on note un engouement des petits paysans pour la production du palmier à huile (Follin, 2000), et la superficie des palmeraies villageoises est passée de 383 ha en 1992 à plus de 15000 ha en 2008 (Adjadi, 2008). Les plus importantes superficies (plus de 9000 ha entre 2006 et 2012) de terres cultivées avec le matériel végétal sélectionné du palmier à huile se retrouvent dans les départements de l'Ouémé et du Plateau au Sud-Est du pays (Adjadi, 2012).

Bien que plantées avec la même densité de palmiers sélectionnés, les palmeraies villagoises béninoises s'écartent des modèles agro-industriels en raison de la diversité des systèmes culturaux pratiqués : diverses associations de cultures vivrières, divers modes de fertilisation et de gestion des feuilles élaguées.

Cette diversité des pratiques culturales nous a amené à proposer une étude agropédologique des palmeraies villageoises dont la première étape a été d'établir leur typologie. Selon Perrot et Landais (1993), face à l'extrême diversité des situations à décrire, les typologies ont l'ambition de constituer un jeu de types qui simplifie la réalité tout en respectant les particularités principales. Les typologies d'exploitations agricoles permettent de définir des groupes cibles d'exploitations, de comparer ces exploitations et de juger de leur fonctionnement, pour des interventions efficaces (Mbetid-Bessane et al., 2002). Elles ont pour objectif de fournir à l'usage des décideurs une image de l'activité agricole locale pour orienter les actions de développement (Arbelot et al., 1997).

L'objectif de ce travail est d'établir la typologie des palmeraies villageoises afin de proposer aux acteurs de la recherche et du développement agricole, un outil d'aide à la décision et de choix raisonné de palmeraies pour des actions en milieu paysan. Nous formulons l'hypothèse qu'il existe dans la zone d'étude des types de palmeraies villageoises qui se distinguent par des facteurs pédologiques, agronomiques et socioéconomiques différentes. 
MATERIEL ET METHODES

\section{Zone d'étude}

La zone d'étude est le département du Plateau situé au sud-est du Bénin (Figure 1). Il est composé de cinq (5) communes : Kétou, Pobè, Adja-Ouèrè, Sakété et Ifangni. La pluviométrie annuelle moyenne dans la zone est de $1300 \mathrm{~mm}$; elle présente une répartition de type bimodal caractéristique du climat subéquatorial avec des déficits hydriques très marqués en saison sèche (Azontondé, 1991 ; Nouy et al., 1999). La végétation est dominée par des savanes arborées et arbustives, des palmeraies plantées avec le matériel végétal sélectionné appelées communément "palmeraies sélectionnées", et des palmeraies issues de régénération naturelle (désignées par "palmeraies naturelles"), des jachères arbustives, des îlots de forêts semi-décidues, des galeries forestières et des mangroves (Djègui, 1992 ; CBD, 2001).

$\mathrm{La}$ couverture pédologique est constituée principalement de sols rouges ferrallitiques formés sur le Continental Terminal, de vertisols et sols à caractère vertique, de sols hydromorphes et de sols ferrugineux tropicaux (Volkoff, 1976 a ; Volkoff et Willaime, 1976 ; Agossou, 1983 ; Azontondé, 1991).

\section{Collecte de données}

Les grandes étapes de cette partie sont présentées sur la Figure 2.

\section{Phase préparatoire}

Une recherche documentaire a permis de connaître les organisations des producteurs de palmier à huile au sein des villages, communes et départements. Le traitement des cartes administrative, topographique, pédologique et de couverture du sol (IGN, 1968 ; Volkoff, 1976 b ; CENATEL, 2009) a abouti à la création d'un système d'information géographique, en utilisant le logiciel Quantum GIS version 1.8.0 (Quantum GIS Development Team, 2013).
Une enquête institutionnelle a été réalisée auprès des organisations villageoises, communales et régionales de planteurs, du Centre d'Action Régionale pour le Développement Rural (CARDER) et de la station de recherche sur le palmier à huile dénommée Centre de Recherches Agricoles Plantes Pérennes (CRA-PP) de Pobè. Pour identifier l'importance relative des communes en matière de culture du palmier à huile sélectionné, un recensement des producteurs de chaque commune a été fait et complété par les superficies plantées et les villages de rattachement en utilisant les informations collectées dans la phase préparatoire.

\section{Phase de terrain}

La collecte des données a été faite à deux échelles correspondant à deux niveaux de typologie des palmeraies villageoises : (i) typologie globale des palmeraies sélectionnées du département du plateau et (ii) typologie spécifique des palmeraies sélectionnées installées sur le type de sol le plus planté (TSPP).

Le choix des variables ayant servi à ces deux niveaux de typologie s'est basé sur les concepts et les théories de Smith et al. (2004) et de Kossoumna Liba'a et Havard (2006) qui considèrent que les variables d'une étude de typologie des agrosystèmes peuvent être de nature sociologique, climatique, agronomique, économique.

- Typologie globale des palmeraies sélectionnées

En tenant compte des informations collectées lors de la phase préparatoire, qui montrent l'inexistence de la production du palmier à huile dans la commune de Kétou, la typologie globale s'est focalisée sur les communes d'Adja-Ouèrè, de Sakété, de Pobè et d'Ifangni. A partir de la liste des producteurs recensés, un groupe de 20 personnes a été sélectionné de façon aléatoire par commune pour l'enquête. Ce groupe comprend de simples producteurs, de personnes détenant des informations fiables 
sur la commune (personnes ressources), et parfois de membres du bureau de l'union communale des producteurs de palmier à huile (UCPPH). Des entretiens semi-structurés ont été effectués en assemblée générale avec chaque groupe et des variables accessibles à cette échelle globale ont été collectées : les types de sol, l'origine des plants sélectionnés, les superficies plantées, les passés culturaux des plantations et les pratiques culturales appliquées dans les palmeraies. Ces informations ont été utilisées pour établir la typologie globale.

- Typologie spécifique des palmeraies sélectionnées installées sur le type de sol le plus planté (TSPP)

Pour des raisons logistiques et du fait de la localisation de la station de recherche, l'enquête individuelle auprès des propriétaires de palmeraies se trouvant sur le TSPP s'est déroulée dans les communes d'Adja-Ouèrè, de Sakété et de Pobè où est localisée la station de recherche. Ces palmeraies forment une population $\mathrm{N}$ de 299 planteurs. En tenant compte des informations collectées en assemblée générale et relatives aux techniques culturales de gestion des sols dans les palmeraies, une enquête sommaire a permis d'avoir la population $\mathrm{p}$ d'individus qui appliquent au moins une technique culturale non pratiquée dans toutes les palmeraies. L'échantillon $n$ de producteurs enquêtés sur le TSPP a été déterminé selon l'équation de distribution binomiale (Dagnelie, 1998) ciaprès.

$n=\frac{U_{1-\alpha / 2}^{2} \times p(1-p)}{d^{2}}$

$\mathrm{n}=$ taille de l'échantillon ;

est la valeur

de la variable normale aléatoire; pour une valeur de probabilité de $\alpha=0,05 ; \mathrm{U}_{1-\alpha / 2}^{2}=$ 1,96 ; $\mathrm{p}$ représente la proportion d'individus qui appliquent au moins une technique culturale non commune à toutes les palmeraies ; d est l'erreur marginale fixée à $10 \%$. On obtient $\mathrm{n}=88,5$ arrondi à 90 producteurs choisis de façon aléatoire parmi la population N. Etant donné que certains producteurs disposent de plusieurs plantations, les informations ont été collectées pour un total de 188 palmeraies sur le TSPP.

Des entretiens semi-structurés ont été effectués individuellement avec les 90 producteurs pour établir la typologie spécifique des palmeraies se trouvant sur le TSPP. Les informations collectées en assemblée générale, notamment sur la taille des exploitations et les techniques culturales pratiquées, ont permis de définir les variables étudiées sur le TSPP. Ces variables sont : l'âge des palmeraies, la superficie, le passé cultural, et les pratiques culturales dont en particulier les associations de cultures vivrières, la fertilisation et les modes de gestion des feuilles d'élagage des palmiers. L'enquête individuelle a renseigné ces variables et des visites de champs ont été effectuées pour vérifier les informations fournies.

\section{Analyse des données}

Les informations collectées au cours des phases d'enquête institutionnelle et en assemblée générale ont été utilisées pour une analyse descriptive. Selon la nature de certaines informations, l'analyse a été participative avec les producteurs qui ont apprécié et pondéré certaines caractéristiques des palmeraies. Quant aux données collectées auprès des 90 producteurs sur les 188 palmeraies du TSPP, elles sont à la fois quantitatives et qualitatives et ont été codifiées et saisies dans le logiciel Microsoft Excel $^{\circledR}$ 2007. Les superficies plantées ont été calculées pour chacun de ces producteurs et ont permis d'identifier les catégories de producteurs se trouvant sur le TSPP. Ces catégories ont été ajoutées aux variables collectées à l'échelle du TSPP afin de réaliser une analyse factorielle des correspondances multiples (AFCM) pour une description des relations entre les modalités des variables. Ces analyses ont été réalisées avec le logiciel XLSTAT $^{\circledR}$.V.2011.4.02. 


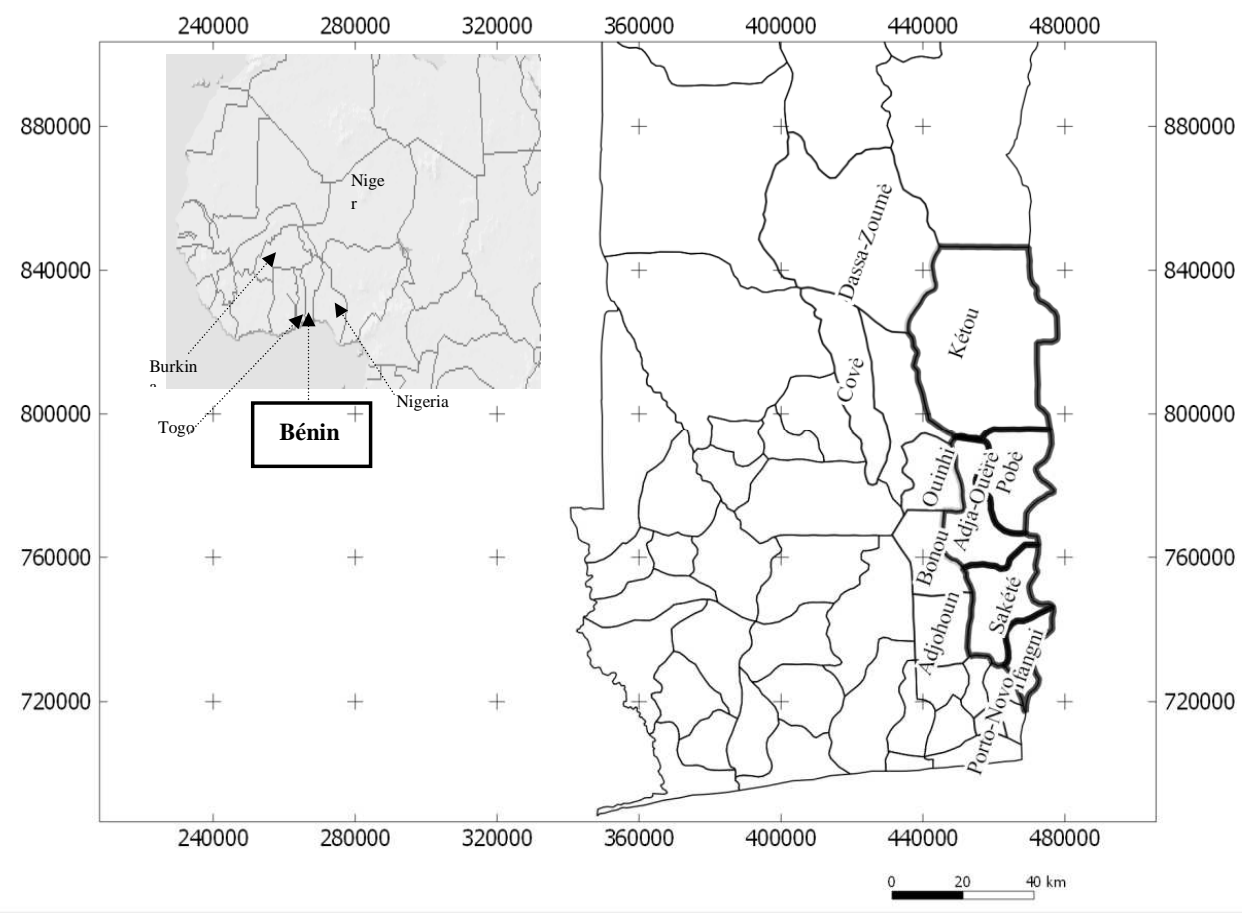

Figure 1: Localisation géographique de la zone d'étude. Les communes à contour gras désignent les 5 communes de la zone d'étude (Département du Plateau).

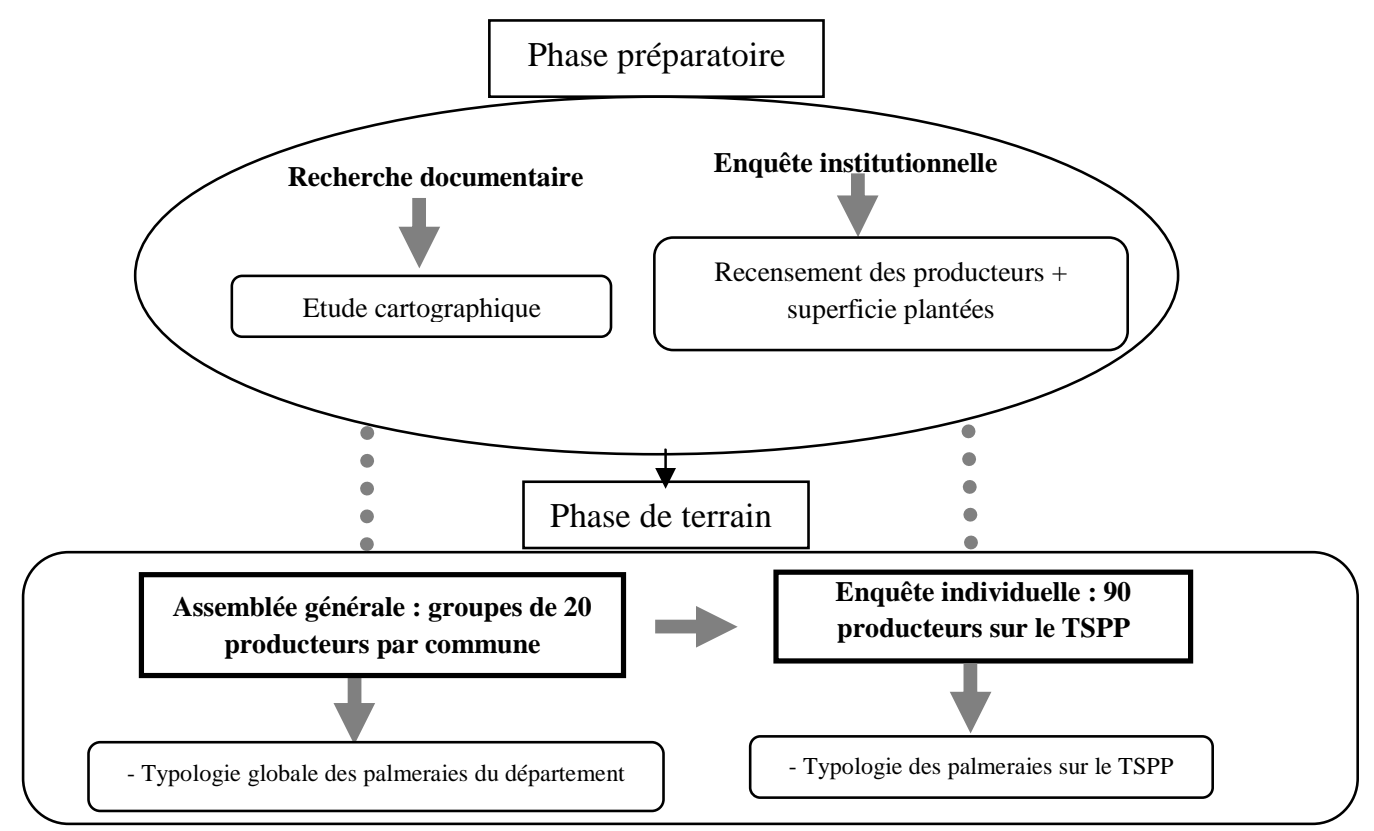

Figure 2 : Les grandes étapes de la collecte des données. TSPP indique le type de sol le plus planté avec le palmier à huile. 


\section{RESULTATS}

Classes de sols et importance des
palmeraies

$\mathrm{La}$ couverture pédologique $\mathrm{du}$ département du Plateau est composée de quatre grandes classes de sols : les sols hydromorphes, les vertisols, les sols ferrugineux tropicaux et les sols ferrallitiques faiblement désaturés. Dans la commune de Kétou, on rencontre plus fréquemment les sols ferrugineux tropicaux appauvris sans concrétions sur granite calco-alcalin à biotite et à concrétions sur embrèchite et granite et les sols ferrallitiques à faciès induré sur grès du crétacé. Dans l'ensemble des quatre autres communes, ce sont les sols ferrallitiques qui dominent (Figure 3a). Ces sols représentent $65 \%$ de la couverture pédologique du département (Figure 3b). Les terres de barre (sols ferrallitiques formés sur sédiment meuble argilo-sableux du Continental Terminal) constituent la sous-classe dominante $(49 \%)$ des sols ferrallitiques (Figure 3c). Elles représentent le type de sol le plus planté (TSPP) avec le palmier à huile dans le département du Plateau et couvrent majoritairement les communes de Sakété, d'Ifangni et d'Adja-Ouèrè (Figure 3a).

L'étude a révélé que la culture du palmier à huile sélectionné se fait essentiellement dans les communes d'AdjaOuèrè, de Pobè, de Sakété et d'Ifangni. Soixante-trois (63) planteurs ont été dénombrés dans la commune de Pobè, 81 planteurs dans Ifangni, 272 planteurs dans Adja-Ouèrè et 196 planteurs dans Sakété.

\section{Caractéristiques générales des plantations de palmier à huile sélectionné \\ Matériel végétal et création des plantations}

Les palmiers sélectionnés proviennent du CRA-PP ou des pépinières agréées par la station. Il s'agit systématiquement de matériel végétal sélectionné représenté par différentes catégories de variétés issues de l'amélioration de l'hybride tenera qui provient du croisement entre dura et pisifera. Ces catégories de variétés améliorées ont des origines génétiques Déli (Indonésie) x La Mé (Côte d'Ivoire) ou Déli x Yangambi (Congo).

La plantation se fait généralement pendant les trois premiers mois de la grande saison des pluies, d'avril à juin. Les plantations villageoises de palmier à huile sélectionné sont installées suivant le dispositif des plantations industrielles, en triangles équilatéraux de $9 \mathrm{~m}$ de côté, soit une densité de plantation de 143 arbres à l'hectare. Les planteurs ajoutent parfois quelques plants en bordure du champ, ce qui porte la densité à environ 150 plants à l'hectare.

\section{Taille et âge des exploitations}

Les producteurs ont défini trois catégories de planteurs en fonction de leurs superficies plantées (SP) : les petits planteurs : $\mathrm{SP}<10$ ha ; les planteurs moyens : $\mathrm{SP}=10$ à 30 ha; et les grands producteurs : SP > 30 ha.

Les premières récoltes de régimes interviennent entre 4 et 5 ans et l'exploitation est conduite pendant au moins 25 ans avant une éventuelle replantation par le paysan. Au cours de ce cycle, le développement de la plante et le mode de récolte de régimes permettent de distinguer différents stades végétatifs. Les paysans ont défini 4 classes d'âges de palmeraies en fonction du rendement en régimes par arbre et des outils de récolte (ciseaux, hache et faucille). Des observations de terrain effectuées au cours de cette étude, ont complété la perception paysanne et ont permis de présenter dans le Tableau 1 les quatre classes d'âges qui distinguent l'état végétatif des palmiers, le rendement en fruits et les modes de récolte.

\section{Passé cultural et techniques culturales dans les palmeraies villageoises}

Il faut distinguer le passé cultural des palmeraies et les techniques culturales pratiquées dans la plantation.

\section{Typologie selon le passé cultural}

Les passés culturaux des palmeraies villageoises sont présentés dans le Tableau 2. 
On distingue deux sortes de palmeraies : les palmeraies de type extension (ou premier cycle) qui n'ont pas été créées après une palmeraie existante (sélectionnée ou de régénération naturelle), par opposition aux palmeraies de type replantation. Exceptionnellement, les palmeraies sur d'anciennes jachères abritant quelques rares palmiers naturels ont été considérées comme des extensions. Aux dires des paysans un faible nombre de palmeraies sont en replantation dans la région d'étude.

Typologie selon les techniques culturales dans les palmeraies

Deux types de techniques culturales caractérisent les plantations villageoises de la zone d'étude : les techniques d'entretien de la plantation et celles de gestion du sol.

- les techniques d'entretien consistent généralement à l'ablation des fleurs au jeune âge (de 18 à 36 mois), au fauchage des recrus des interlignes de plantation après arrêt des cultures intercalaires (une à deux fois par an) et l'élagage annuel des feuilles non fonctionnelles des palmiers.

- quant aux techniques de gestion du sol elles sont caractérisées par une association systématique des cultures vivrières (maïs, tomate, niébé, arachide, manioc, piment, patate douce...) jusqu'à 4-5 ans d'âge des palmiers, un apport occasionnel d'engrais $\mathrm{NKP}, \mathrm{KCl}$ et urée et une fertilisation organique par restitution ou non des sousproduits d'usinage des fruits de palmier et des feuilles d'élagage.

Les planteurs disposant d'unités de transformation des fruits ont déclaré restituer les sous-produits d'usinage (rafles, tourteaux...) dans les palmeraies.

La fertilisation chimique du palmier à huile se fait de façon très irrégulière et les formes et doses d'engrais ne sont pas respectées dans la plupart des cas. Le Tableau 3 présente les doses d'engrais recommandées par la station de recherche sur le palmier à huile et celles appliquées par la majorité des producteurs qui font l'effort d'un apport de fumures minérales aux palmiers. D’une façon générale, les doses apportées par les paysans sont inférieures aux prescriptions de la recherche. De plus, les paysans ne respectent pas les périodes d'apport recommandées. L'apport d'azote sous forme d'urée est privilégié au jeune âge. Les paysans ont affirmé que l'urée constitue parfois le seul type d'engrais appliqué jusqu'à l'entrée en récolte. Après 5 ans, ils privilégient l'apport du $\mathrm{KCl}$ ou du NPK et y associent parfois l'urée. Les doses d'engrais appliquées par les paysans sont fonction de la disponibilité des engrais et des moyens financiers dont dispose le producteur.

L'enquête a permis d'identifier 5 modes de gestion des feuilles d'élagage dans les palmeraies villageoises qui sont présentés dans le Tableau 4. On constate que la gestion des feuilles d'élagage va du mode de restitution nulle à celui de la restitution totale. Dans le cas des modes de restitution, les feuilles peuvent être rangées en andain entre deux arbres sur la ligne de plantation ou disposées en vrac dans la palmeraie. La Photo 1 illustre le mode de restitution des feuilles en andain dans une palmeraie.

\section{Caractéristiques des palmeraies plantées sur les terres de barre}

Les proportions des catégories de producteurs sont présentées en Figure 4 qui montre que les producteurs de la zone d'étude sont majoritairement $(93 \%)$ des petits planteurs (SP $<10$ ha).

Les caractéristiques des 188 palmeraies étudiées sur terre de barre dans les communes de Pobè, Adja-Ouèré et Sakété, et les proportions de leurs modalités sont présentées dans le Tableau 5. Les enseignements tirés sont les suivants :

- les palmeraies sont majoritairement localisées dans les communes d'Adja-Ouèrè et de Sakété. Elles sont pour la plupart de type 
extension et les cultures vivrières dominent dans leur passé cultural ;

- $67 \%$ des palmeraies sont d'âges supérieurs à 7 ans et font l'objet de différents modes de gestion des feuilles d'élagage ;

- $65 \%$ des palmeraies ont été ou sont associées au jeune âge à diverses cultures vivrières ;

- $87 \%$ des palmeraies sont peu ou pas (20,5\%) fertilisées et dans $2 / 5$ ième des cas, les engrais utilisés ne sont pas ceux recommandés par la recherche ;

- la fertilisation organique est très peu pratiquée et les feuilles d'élagage sont exportées (totalement ou partiellement) dans plus de $80 \%$ des cas.

La Figure 5 tirée de l'analyse factorielle des correspondances multiples, permet de distinguer 4 groupes de palmeraies qui sont caractérisés par des variables ayant des relations entre elles. Le Tableau 6 présente quelques caractéristiques de ces groupes de palmeraies qui sont : les types de planteurs appartenant à chaque groupe, les âges des palmeraies et leur superficie, puis les modes de fertilisation minérale et de gestion des feuilles.

Les palmeraies du groupe 1 ont des superficies élevées (sup3 et sup4) et appartiennent aux grands producteurs. Ces producteurs appliquent les doses d'engrais recommandées (Dfum1) recyclent les déchets de transformation et font une restitution totale ou partielle des feuilles d'élagage en andains. Les palmeraies de ce groupe représentent $13 \%$ de l'effectif des palmeraies sur terre de barre et occupe $49 \%$ des superficies plantées (Tableau 6). Elles sont localisées dans les communes d'Adja-Ouèrè et de Sakété et sont installées sur d'anciennes jachères arbustives d'âge estimé à plus d'une dizaine d'années par les producteurs.

A l'opposé du groupe 1, le groupe 2 est composé de palmeraies appartenant aux petits producteurs, de superficies plantées inférieures à 5 ha (Sup1). Les palmeraies de ce groupe couvrent $31 \%$ de la superficie totale plantée et représentent $67 \%$ du nombre de palmeraies étudiées sur terres de barre (Tableau 6). Les exploitants du groupe 2 ne respectent pas les doses d'engrais recommandées (Dfum0). Il n'y a pas de recyclage des sous-produits de transformation et les feuilles d'élagage sont totalement exportées pour servir principalement de combustible. Les associations culturales au jeune âge de plantation se font souvent avec le maïs et les légumineuses (Figure 5). Les parcelles de ces plantations étaient cultivées avant le palmier avec diverses cultures vivrières : maïs, niébé, arachide, manioc, tomate, piment, patate douce...

$>\quad$ Le groupe 3 est constitué en majorité de jeunes palmeraies (Age1) qui ne sont pas encore entrées en production, et qui reçoivent de façon irrégulière les doses et types d'engrais (Applfum1). On rencontre les palmeraies de ce groupe dans les 3 communes étudiées et elles appartiennent pour la plupart aux petits et aux grands producteurs.

Les palmeraies du groupe 4 se retrouvent majoritairement dans la commune de Sakété (Loparc-sak), où l'association du palmier avec le maïs et le manioc au jeune âge est fréquente (Assocv2 et Assocv3). Les engrais ne sont pas appliqués (Applfum0). Les feuilles d'élagage partiellement restituées sont disposées en vrac (Gfeuil2).

La Figure 6 présente les proportions des modes de gestion des feuilles d'élagage en fonction des âges des palmeraies concernées (palmeraies d'âges $>7$ ans). On constate que quelle que soit la classe d'âge, l'exportation totale ou partielle des feuilles $(\mathrm{RN}+\mathrm{RPV}+\mathrm{RPA})$ est la pratique la plus répandue. On note dans la classe d'âge 13-20 ans une part importante $(31,7 \%)$ du mode de restitution totale en andain (RTA) par rapport aux autres âges. 
(a)
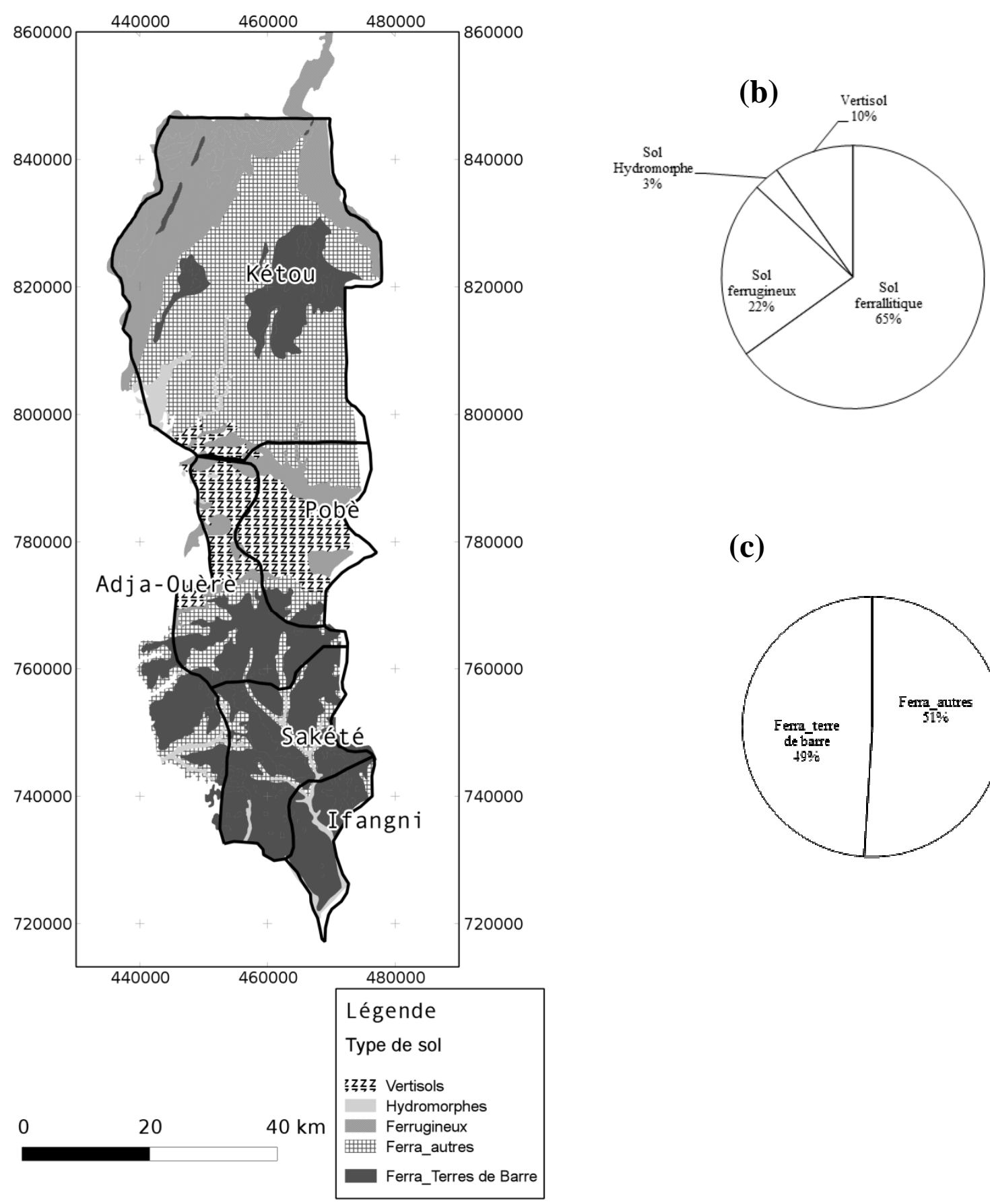

(c)

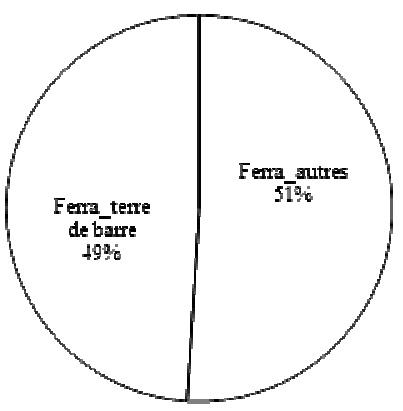

Figure 3 : Les différents types de sol dans le département (a), leurs proportions (b), et la proportion des terres de barre parmi les sols ferrallitiques (c). Ferra-Terres de barre désigne la sous classe de sols ferrallitiques sur continental terminal Ferra-autres désigne les autres sous-classes de sols ferrallitiques. 


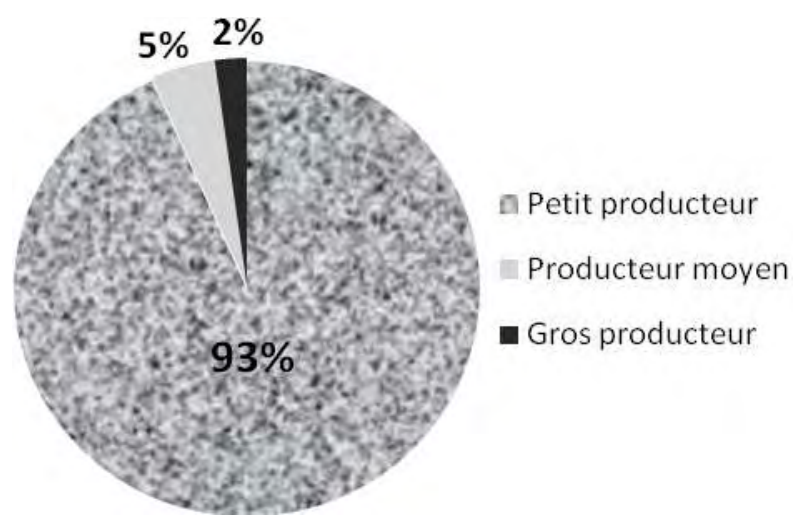

Figure 4 : Proportion relative des types de producteurs de palmier à huile sélectionné installé sur terres de barre. Typologie établie selon les superficies plantées, nombre de producteurs $=90$. Petits producteurs : superficie totale plantée $<10$ ha ; producteurs moyens : 10 ha $<$ superficie totale plantée $<30$ ha ; grands producteurs : superficie totale plantée $\geq 30$ ha.

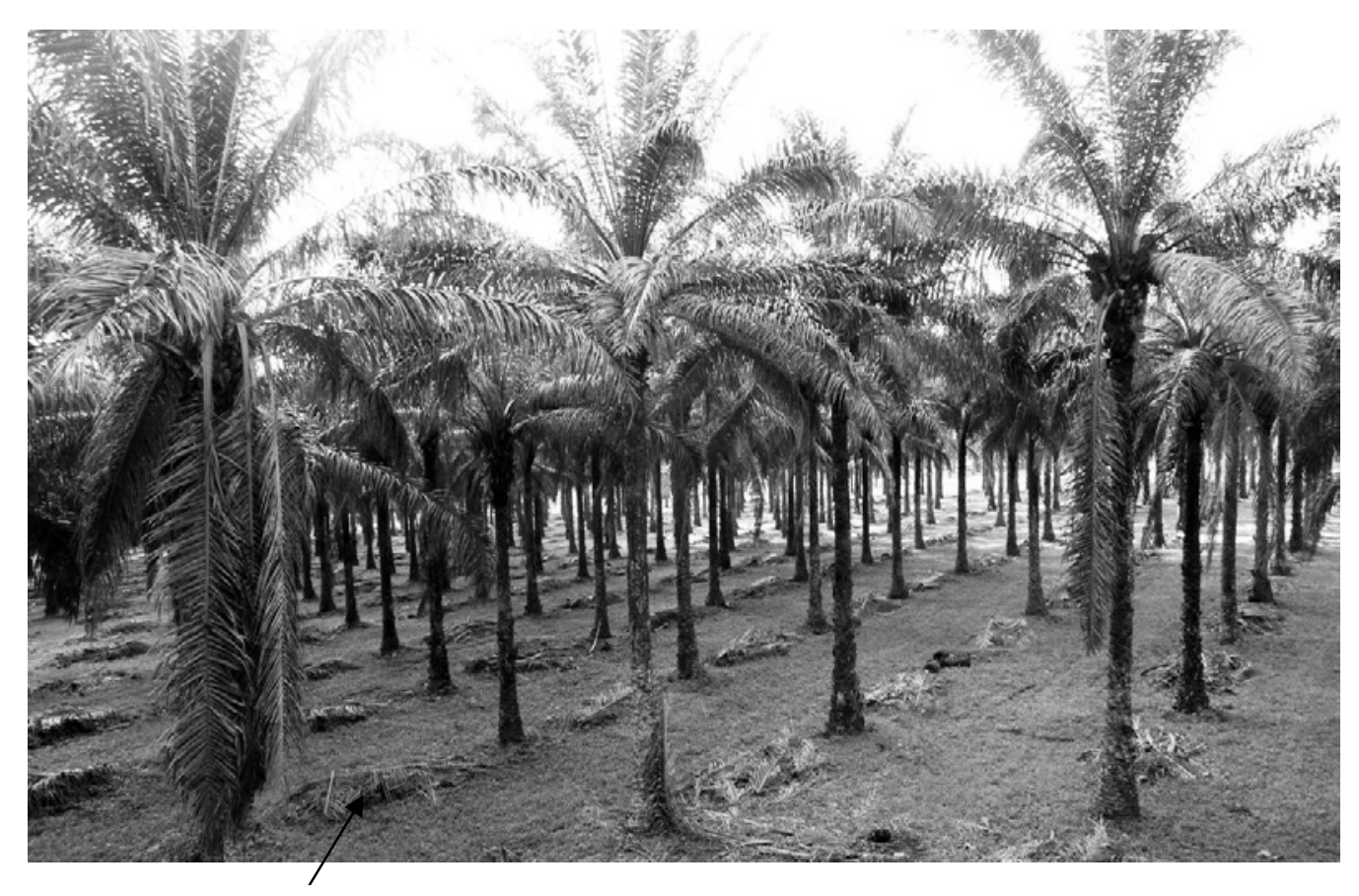

Andain de feuilles de palmiers

Photo 1 : Dispositif de restitution en andain des feuilles dans une palmeraie au Bénin. 


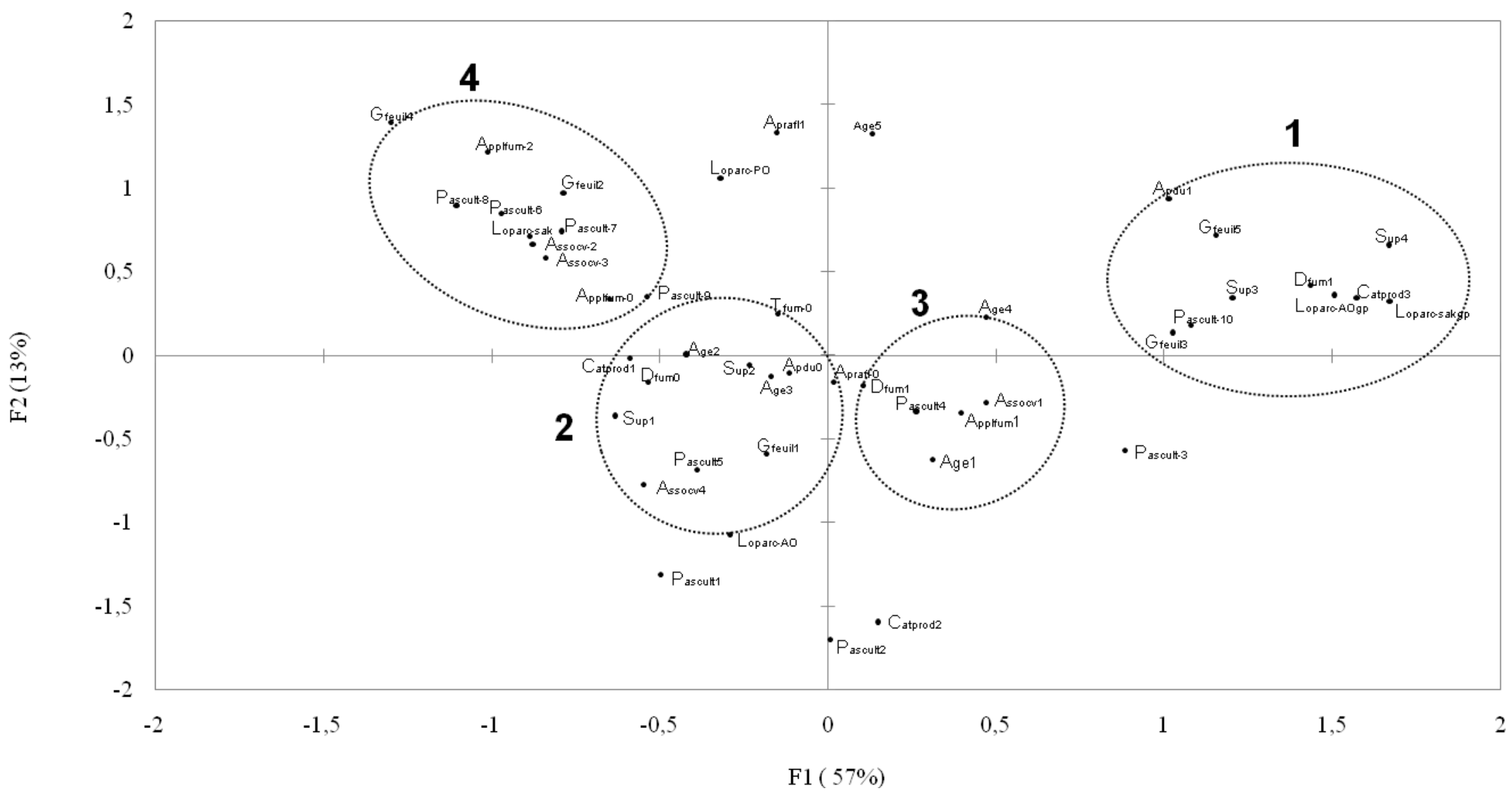

Figure 5: Projection des caractéristiques des parcelles des 90 producteurs dans le TSPP sur les axes F1 et F2 de l'analyse factorielle en composantes multiples. Age = classe d'âge ; Sup $=$ superficie $;$ Pascult $=$ passé cultural $;$ AssoCv $=$ association de cultures vivrières; Aprafl $=$ apport de rafles dans les ronds; Apdu $=$ apport sous-produits de transformation ; Gfeuil $=$ mode de gestion des feuilles d'élagage; Tfum = type de fumure $;$ Dfum = dose de fumure ; Applfum = régularité d'application de fumure ; Catprod = catégorie de producteurs. 


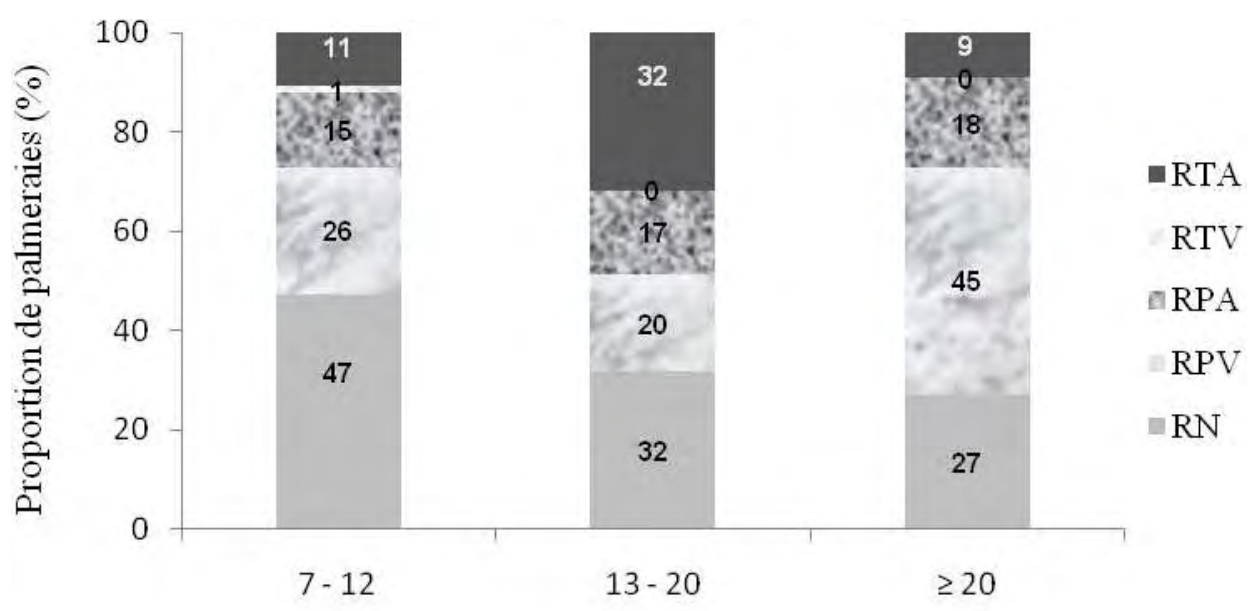

Age (ans)

Figure 6 : Proportion des types de palmeraies par classe d'âge selon le mode de gestion des feuilles. Les codes mnémoniques RTA, RTV, RPA, RPV et RN désignent respectivement Restitution Totale en Andain, Restitution Totale en Vrac, Restitution Partielle en Andain, Restitution Partielle en Vrac et Restitution Nulle.

Tableau 1: Principales phases de développement des palmeraies et leurs caractéristiques selon la perception paysanne.

\begin{tabular}{|c|c|c|c|}
\hline $\begin{array}{l}\text { Ages } \\
\text { (ans) }\end{array}$ & $\begin{array}{c}\text { Type de } \\
\text { plantation }\end{array}$ & Etat végétatif de la plantation & Mode de récolte \\
\hline $0-6$ & Jeune & $\begin{array}{l}\text { Installation végétative du plant ; colonisation } \\
\text { progressive du milieu par le système racinaire } \\
\text { première production de régimes ; arrêt de } \\
\text { cultures intercalaires entre } 4 \text { et } 5 \text { ans. }\end{array}$ & Récolte au ciseau \\
\hline $7-12$ & Pré-adulte & $\begin{array}{l}\text { Canopée non fermée; présence de recrûs ligneux } \\
\text { sous palmeraie ; rendement en augmentation. }\end{array}$ & Récolte à la hache. \\
\hline $13-24$ & Adulte & $\begin{array}{l}\text { Canopée fermée ; moins de luminosité ; } \\
\text { régression des recrûs ; rendement maximum vers } \\
15 \text { ans. }\end{array}$ & $\begin{array}{l}\text { Récolte à la faucille ou } \\
\text { à la hache en grimpant } \\
\text { dans l'arbre avec un } \\
\text { cerceau. }\end{array}$ \\
\hline$\geq 25$ & Vieux & $\begin{array}{l}\text { Eclaircissement de la canopée ; augmentation } \\
\text { des recrûs ; rendement en baisse ; perte des } \\
\text { bases pétiolaires du stipe. }\end{array}$ & $\begin{array}{l}\text { Récolte à la faucille ou } \\
\text { à la hache en grimpant } \\
\text { dans l'arbre avec un } \\
\text { cerceau. }\end{array}$ \\
\hline
\end{tabular}


Tableau 2: types de palmeraies selon le passé cultural.

\begin{tabular}{|c|c|c|c|c|c|c|}
\hline \multicolumn{4}{|c|}{ Palmeraie de type extension } & \multicolumn{3}{|c|}{ Palmeraie de type replantation } \\
\hline \multicolumn{4}{|c|}{ Passé cultural } & \multicolumn{3}{|c|}{ Passé cultural } \\
\hline $\begin{array}{l}\text { Ancienne } \\
\text { jachère } \\
\text { arborée ou } \\
\text { forêt } \\
\text { secondaire }\end{array}$ & $\begin{array}{l}\text { Ancienne } \\
\text { jachère } \\
\text { arborée } \\
\text { avec } \\
\text { quelques } \\
\text { rares } \\
\text { palmiers } \\
\text { naturels }\end{array}$ & $\begin{array}{c}\text { Champ de } \\
\text { cultures } \\
\text { vivrières } \\
\text { (maïs, niébé, } \\
\text { arachide, } \\
\text { manioc, } \\
\text { tomate, } \\
\text { piment...) }\end{array}$ & $\begin{array}{l}\text { Champ de } \\
\text { cultures } \\
\text { vivrières et } \\
\text { quelques } \\
\text { pieds de } \\
\text { palmiers } \\
\text { naturels }\end{array}$ & $\begin{array}{c}\text { Palmeraie } \\
\text { sélectionnée } \\
\text { de densité } \\
143 \\
\text { arbres/ha }\end{array}$ & $\begin{array}{l}\text { Palmeraie } \\
\text { naturelle à } \\
\text { densité } \\
\text { réduite (80 } \\
\text { à } 100 \\
\text { arbres/ha) + } \\
\text { association } \\
\text { permanente } \\
\text { de cultures } \\
\text { vivrières }\end{array}$ & $\begin{array}{c}\text { Palmeraie } \\
\text { naturelle en } \\
\text { culture } \\
\text { pure de } \\
\text { densité } 143 \\
\text { arbres } / \text { ha }\end{array}$ \\
\hline
\end{tabular}

* Palmeraie naturelle désigne une plantation de palmiers à huile issus de régénération naturelle et dont les fruits sont ramassés par les producteurs pour servir de semences aux nouvelles plantations.

Tableau 3: Doses de fumures recommandées par le CRAPP de Pobè sur le palmier à huile et celles appliquées par les paysans.

\begin{tabular}{|c|c|c|c|c|c|c|c|}
\hline Engrais & Dose & An 0 & An 1 & An 2 & An 3 & An 4 & An 5 \\
\hline \multirow[t]{2}{*}{$\begin{array}{c}\text { Urée } \\
\text { (g/plant) }\end{array}$} & $\mathrm{R}$ & $\begin{array}{c}150\left(1^{\mathrm{er}} \text { apport }\right)+ \\
200\left(2^{\mathrm{e}} \text { apport }\right)\end{array}$ & $\begin{array}{c}200\left(1^{\mathrm{er}}\right. \\
\text { apport })+200 \\
\left(2^{\mathrm{e}} \text { apport }\right)\end{array}$ & $\begin{array}{c}250\left(1^{\mathrm{er}}\right. \\
\text { apport })+250 \\
\left(2^{\mathrm{e}} \text { apport }\right)\end{array}$ & 500 & 500 & $\begin{array}{l}\text { Selon DF ou } \\
\text { apport de } 750 \\
\text { g à } 1000 \mathrm{~g}\end{array}$ \\
\hline & $\mathrm{P}$ & 0 & 300 & 300 & 250 & 250 & 250 \\
\hline \multirow{2}{*}{$\begin{array}{l}\text { Chlorure } \\
\text { de } \\
\text { potassium } \\
\text { (g/plant) }\end{array}$} & $\mathrm{R}$ & 200 & 200 & 500 & 500 & 500 & $\begin{array}{l}\text { Selon DF ou } \\
\text { apport de } 500 \\
\text { g à } 750 \mathrm{~g}\end{array}$ \\
\hline & $\mathrm{P}$ & 0 & 0 & 250 & 250 & 450 & 500 \\
\hline
\end{tabular}

$\mathrm{R}=$ doses recommandées par le Centre de Recherches Agricoles Plantes Pérennes (CRAPP).

$\mathrm{P}=$ dose appliquée par les paysans.

$\mathrm{DF}=$ diagnostic foliaire réalisé par détermination chimique des teneurs foliaires en $\mathrm{N}, \mathrm{P}, \mathrm{K}, \mathrm{Ca}$ et $\mathrm{Mg}$. 
Tableau 4: Modes de restitution des feuilles d'élagage des palmiers.

\begin{tabular}{lcc}
\hline $\begin{array}{l}\text { Mode de gestion des feuilles } \\
\text { d'élagage }\end{array}$ & $\begin{array}{c}\text { Code } \\
\text { mnémo }\end{array}$ & Description \\
\hline $\begin{array}{l}\text { Restitution totale en andain } \\
\text { (exportation quasi-nulle) }\end{array}$ & RTA & $\begin{array}{c}\text { Retour de presque toutes les feuilles d'élagage au sol; } \\
\text { elles sont rangées en andain, sur la ligne de plantation } \\
\text { (Photo ci-après). Très peu de feuilles sont collectées } \\
\text { par les paysans. }\end{array}$ \\
\hline $\begin{array}{l}\text { Restitution totale en vrac } \\
\text { (exportation quasi- nulle) }\end{array}$ & RTV & $\begin{array}{c}\text { Retour des feuilles d'élagage au sol sans dispositif } \\
\text { particulier (au hasard sur toute la surface). Très peu } \\
\text { de feuilles sont collectées par les paysans. }\end{array}$ \\
\hline $\begin{array}{l}\text { Restitution partielle en andain } \\
\text { (exportation partielle) }\end{array}$ & RPA & $\begin{array}{c}\text { Retour des feuilles d'élagage au sol et rangées en } \\
\text { andain. Une partie de ces feuilles sont prélevées par } \\
\text { les villageois pour usage domestique (bois de feu). }\end{array}$ \\
\hline $\begin{array}{l}\text { Restitution partielle en vrac } \\
\text { (exportation partielle) }\end{array}$ & RPV & $\begin{array}{c}\text { Retour des feuilles d'élagage au sol sans dispositif } \\
\text { particulier (au hasard sur toute la surface). Une partie } \\
\text { de ces feuilles sont prélevées par les villageois pour } \\
\text { usage domestique. }\end{array}$ \\
\hline $\begin{array}{l}\text { Restitution nulle } \\
\text { (exportation totale) }\end{array}$ & RN & $\begin{array}{l}\text { Toutes les feuilles sont ramassées par les villageois } \\
\text { pour des usages domestiques. }\end{array}$ \\
\hline
\end{tabular}

Tableau 5: caractéristiques des palmeraies sur terre de barre.

\begin{tabular}{lccc}
\hline Variable & Modalités & $\begin{array}{c}\text { Code } \\
\text { AFCM }\end{array}$ & $\begin{array}{c}\text { Pourcen } \\
\text { tage }(\boldsymbol{\%})\end{array}$ \\
\hline \multirow{2}{*}{ Localisation parcelle } & Adja-Ouèrè & 51,1 \\
& Pobè & 7,4 \\
& Sakété & Age1 & 12,8 \\
Age (an) & $<4$ & Age2 & 20,2 \\
& $4-6$ & Age3 & 39,4 \\
& $7-12$ & Age4 & 21,8 \\
& $13-20$ & Age5 & 5,9 \\
\hline \multirow{2}{*}{ Superficie (ha) } & $>20$ & Sup1 & 11,7 \\
& $<1$ & Sup2 & 71,3 \\
& $1-5$ & Sup3 & 9,6 \\
\hline
\end{tabular}




\begin{tabular}{|c|c|c|c|}
\hline Passé cultural (palmeraie & Diverses cultures vivrières+ rares palmiers naturels & Pascult1 & 5,9 \\
\hline \multirow[t]{2}{*}{ en replantation) } & Palmeraie naturelle & Pascult2 & 1,6 \\
\hline & Palmeraie sélectionnée & Pascult3 & 1,6 \\
\hline \multirow{7}{*}{$\begin{array}{l}\text { Passé cultural (palmeraie } \\
\text { en extension) }\end{array}$} & Diverses cultures vivrières+ rares palmiers naturels & Pascult4 & 14,9 \\
\hline & Diverses cultures vivrières & Pascult5 & 17,6 \\
\hline & Maïs, manioc & Pascult6 & 20,8 \\
\hline & Maïs & Pascult7 & 4,3 \\
\hline & Maïs, légumineuse & Pascult8 & 1,1 \\
\hline & Jachère à palmiers naturels d'au moins 10 ans & Pascult9 & 3,7 \\
\hline & Jachère arborée & Pascult10 & 28,7 \\
\hline Association cultures & Toutes cultures vivrières & AssoCv1 & 63,8 \\
\hline vivrières & Maïs, manioc & AssoCv2 & 23,9 \\
\hline au jeune âge de & Maïs seul & AssoCv3 & 8,5 \\
\hline plantation & Maïs, légumineuse & AssoCv4 & 3,7 \\
\hline \multirow[t]{2}{*}{ Apport de rafles } & Non & Aprafl0 & 89,4 \\
\hline & Oui & Aprafl1 & 10,7 \\
\hline Apport sous-produits de & Non & Apdu0 & 89,9 \\
\hline transformation & Oui & Apdu1 & 10,1 \\
\hline \multirow{5}{*}{ Gestion feuilles d'élagage } & Restitution nulle (RN) & Gfeuil1 & 54,3 \\
\hline & Restitution partielle en vrac (RPV) & Gfeuil2 & 20,8 \\
\hline & Restitution partielle en andain (RPA) & Gfeuil3 & 11,2 \\
\hline & Restitution totale en vrac (RTV) & Gfeuil4 & 0,5 \\
\hline & Restitution totale en andain (RTA) & Gfeuil5 & 13,3 \\
\hline \multirow[t]{2}{*}{ Type fumure minérale } & Non recommandé & Tfum0 & 41,5 \\
\hline & Recommandé & Tfum1 & 58,5 \\
\hline \multirow[t]{2}{*}{ Dose fumure minérale } & Non recommandé & Dfum0 & 72,9 \\
\hline & Recommandé & Dfum1 & 27,1 \\
\hline Application fumure & Sans apport & Applfum0 & 20,7 \\
\hline \multirow[t]{2}{*}{ minérale } & Apport irrégulier & Applfum1 & 66,5 \\
\hline & Apport régulier & Applfum2 & 12,8 \\
\hline
\end{tabular}

Age = classe d'âge; Sup = superficie; Pascult = passé cultural; AssoCv = association de cultures vivrières; Aprafl = apport de rafles dans les ronds; Apdu = apport sous-produits de transformation; Gfeuil = mode de gestion des feuilles d'élagage; Tfum = type de fumure; Dfum = dose de fumure; Applfum = régularité d'application de fumure; Catprod $=$ catégorie de producteur. 
Tableau 6 : Quelques caractéristiques des groupes palmeraies sur terre de barre.

\begin{tabular}{|c|c|c|c|c|c|c|c|}
\hline $\begin{array}{l}\text { Groupes de } \\
\text { palmeraies }\end{array}$ & Types de planteurs & $\begin{array}{c}\text { Gestion des feuilles } \\
\text { d'élagage }\end{array}$ & Fertilisation & Age palmeraie & (\%) palmeraies & $\begin{array}{l}\text { Superficie totale } \\
\text { (ha) }\end{array}$ & (\%) superficie \\
\hline Groupe 1 & Grands producteurs & $\begin{array}{l}\text { - Restitution totale } \\
\text { en andain } \\
\text { - Restitution } \\
\text { partielle en andain }\end{array}$ & $\begin{array}{c}\text { Doses } \\
\text { recommandées de } \\
\text { fumures }\end{array}$ & $\begin{array}{c}\text { Majoritairement } \\
\text { adultes } \\
(13-20 \text { ans })\end{array}$ & 13 & 324 & 49 \\
\hline Groupe 2 & Petits planteurs & - Restitution nulle & $\begin{array}{c}\text { Doses non } \\
\text { recommandées de } \\
\text { fumures }\end{array}$ & $\begin{array}{l}\text { Jeune } \\
(4-6 \text { ans) et } \\
\text { préadulte } \\
(7-12 \text { ans })\end{array}$ & 67 & 208 & 31 \\
\hline Groupe 3 & $\begin{array}{l}\text { Petits et moyens } \\
\text { producteurs }+ \\
\text { quelques grands } \\
\text { producteurs }\end{array}$ & - & $\begin{array}{c}\text { Doses } \\
\text { recommandées de } \\
\text { fumures }\end{array}$ & $\begin{array}{c}\text { Jeune } \\
0 \text { - 4ans et adulte } \\
(13-20 \text { ans })\end{array}$ & 13 & 76 & 12 \\
\hline Groupe 4 & $\begin{array}{c}\text { Petits et moyens } \\
\text { producteurs }\end{array}$ & $\begin{array}{l}\text { - Restitution totale } \\
\text { et partielle en vrac }\end{array}$ & $\begin{array}{c}\text { Pas d'apport ou } \\
\text { apport irrégulier de } \\
\text { fumures }\end{array}$ & - & 7 & 54 & 8 \\
\hline
\end{tabular}




\section{DISCUSSION}

\section{Caractéristiques générales des palmeraies du département du Plateau}

La distribution géographique de la culture du palmier à huile sélectionné est liée à la couverture pédologique du département. Les sols ferrallitiques qui sont les plus favorables à cette culture (Agossou, 1983 ; Elong, 2003) se retrouvent dans les communes d'Adja-Ouèrè, de Sakété et d'Ifangni. Les autres types de sols sont plus fréquents dans les communes de Kétou et de Pobè et offrent des contraintes physiques (notamment texturales) plus importantes que les terres de barre (Azontondé, 1991). Ils sont moins propices à la culture du palmier à huile.

Selon les paysans, les palmeraies ont été d'abord installées sur les sols ferralitiques puis par la suite sur les autres types de sol (hydromorphes et vertisols). Ceci pourrait s'expliquer par la dominance des sols ferralitiques dans le département (Figure 3b) et par la forte présence dans le passé des palmiers naturels sur ces sols (JuhéBeaulaton, 1998). De même, les palmeraies de la station de recherche et celles des coopératives d'aménagement rural, avaient été installées sur les sols ferrallitiques et auraient servi de modèles aux planteurs privés pour leur choix.

Les plantations villageoises sont plus nombreuses dans les communes d'Adja-Ouèrè et de Sakété (Tableau 5) en raison de l'installation historique des coopératives dans ces deux communes qui a suscité un attrait pour cette culture. Cet engouement des paysans s'expliquerait par la diffusion du matériel végétal amélioré par le CRA-PP et les pépiniéristes agréés. Les résultats du recensement des planteurs de palmier à huile sélectionné concordent avec ceux de SNVBénin (2009) et confirment la bonne position occupée par les communes d'Adja-Ouèrè et de Sakété dans la production du palmier à huile sélectionné dans le département du Plateau.

Les paysans ont déclaré que les moyens financiers étaient une limite à la taille des plantations. Ils estiment que sans les ressources financières le producteur ne peut pas planter et entretenir de grandes superficies même s'il pourrait accéder à de telles superficies par un mode de faire valoir direct du foncier (héritage ou achat). En fonction de la superficie totale plantée les producteurs ont défini trois groupes de producteurs. L'importance des petits producteurs dans la zone d'étude est confirmée par les observations faites sur les terres de barre où 93\% des producteurs ont des exploitations de petite taille. Cela indique que la majorité des petits producteurs ont de faibles moyens financiers. Toutefois, on rencontre quelques rares producteurs ayant des moyens financiers importants mais qui disposent de palmeraies de petite taille. Ils ont déclaré avoir volontairement limité leurs superficies en palmier. Bien que peu attirés par cette culture, ils justifient cette petite superficie par le côté prestigieux du palmier à huile.

La prédominance des palmeraies en extension confirme l'adoption récente du palmier à huile sélectionné en plantation villageoise dans le département. Les fortes proportions de palmeraies jeunes (moins de 6 ans d'âge) et pré-adultes (7-12 ans d'âge) rencontrées sur les terres de barre confirment ce caractère récent (Adjé et Adjadi, 2001; Adjadi, 2008). En effet, bien que la variété sélectionnée (tenera) ait été introduite au Bénin depuis les années 1950 (Fournier et al., 2002), elle n'est apparue en plantation villageoise que dans les années 1990 avec le projet de relance de la production du palmier à huile (Adjé et al., 2001; Fournier et al., 2002). Ainsi, les superficies plantées ont connu un accroissement entre 1988 et 1993 et le palmier à huile sélectionné a progressivement pris le pas sur les palmeraies naturelles pour la fourniture des corps gras. Selon Adjadi (2008), la grande expansion de palmeraies villageoises a eu lieu entre 1997 à 2000 quand les superficies plantées ont augmenté de $85 \%$. Ainsi, la plupart des palmeraies villageoises sont toujours en production ou ont été peu replantées. Ce qui explique les affirmations des paysans sur la faible présence des 
palmeraies de type replantation dans le département.

Par rapport aux cultures vivrières, les paysans ont manifesté un intérêt prioritaire pour la culture du palmier à huile qui s'avère plus rémunératrice. Mais en revanche dans leur stratégie d'allocation et de gestion des terres agricoles, ils associent les cultures vivrières aux plants de palmier à huile à leur jeune âge quel que soit le type de système de culture adopté. Ces associations de cultures vivrières au jeune âge de plantation ont été adoptées dans les palmeraies sélectionnées de la même façon qu'elles étaient pratiquées traditionnellement dans les palmeraies naturelles. Elles génèrent des revenus aux paysans et assurent leur subsistance (Chaléard, 2002) avant l'entrée en production du palmier. Selon Dufumier et al. (1997), l'association des cultures vivrières aux cultures pérennes, dans les premières années de plantation, est fréquente en agriculture paysanne. Elle permet de répondre aux besoins alimentaires des exploitants, et d'offrir une rémunération optimale vis-à-vis des coûts de production (terre, travail et maind'œuvre). Dans la zone d'étude, l'entretien périodique des cultures vivrières associées participe fortement à l'entretien des jeunes palmeraies. Dans les systèmes d'association et de rotation des cultures, le recyclage des résidus de récolte profite aux cultures associées par le maintien des stocks de carbone et d'éléments nutritifs dans le sol et par la fourniture d'azote lorsque le système cultural comporte des légumineuses (Deans et al., 1999 ; Barthès et al., 2004 ; Amadji et Aholoukpè, 2008).

Les palmeraies où les feuilles d'élagage sont totalement exportées, sont fréquentes dans le département. Cependant quelques feuilles échappent toujours au ramassage, et les folioles ainsi que l'extrémité apicale du rachis sont parfois abandonnées sur place.

Cette pratique d'exportation des feuilles peu répandue dans d'autres pays à vocation élaeicole (Côte d'Ivoire, Malaisie, Indonésie, Equateur...) (Corley et Tinker, 2003) contribue à une perte de matière organique et d'éléments minéraux à l'échelle de la parcelle. Elle se justifie par les usages qui en sont faits par les populations : construction, alimentation du bétail, combustibles, pharmacopée, usages rituels et autres (Ahoyo, 2008). L'enquête a révélé que l'utilisation des feuilles comme combustible est devenue très courante dans la zone d'étude depuis au moins une décennie. Cette évolution s'explique par la raréfaction du bois issu des forêts dont les prélèvements sont de plus en plus contrôlés par les propriétaires ou les garde - forestiers.

Les palmeraies à restitution totale en andain (RTA) ou restitution totale en vrac (RTV) ont été considérées comme des exportations nulles. En réalité, il arrive que quelques feuilles d'élagage soient exportées, mais toujours en quantité négligeable. Ces palmeraies sont soit surveillées par des gardiens soit situées à au moins $5 \mathrm{Km}$ des habitations. Elles subissent moins la pression des populations pour le besoin en combustible.

Les associations culturales et le recyclage des feuilles d'élagage interviennent dans le stock de matière organique des sols sous palmeraies. Selon Djègui (1995), une variabilité spatiale des stocks de la matière organique des sols sous palmeraie est liée aux pratiques culturales. On peut donc s'interroger sur la durabilité du système des palmeraies villageoises du Bénin lorsque les producteurs arrêtent les associations culturales à 5 ans, puis à partir de 7 ans exportent les feuilles d'élagage jusqu'à la fin du cycle de culture. Une pratique qui pourrait entraîner selon les estimations de Aholoukpè et al. (2013), une exportation annuelle de 10 tonnes de matière sèche à l'hectare. A cela, il faut ajouter la très faible fertilisation des palmeraies. Selon Ton et de Haan (1995), la conservation de la matière organique, le recyclage des éléments nutritifs, l'emploi des fumures, la rotation des cultures et les mesures anti-érosives, sont recommandés pour parvenir un équilibre entre les apports et les prélèvements d'éléments nutritifs, gage d'une agriculture durable. 


\section{Caractéristiques des palmeraies villageoises sur les terres de barre}

Les caractéristiques des palmeraies se trouvant sur les terres de barre sont similaires à celles du département. Les proportions de petits, moyens et grands producteurs peuvent s'expliquer par le fait que la majorité des producteurs disposent de revenus modestes alors que la superficie plantée est surtout limitée par leurs moyens financiers et la maind'œuvre dont ils disposent. Cependant, avec la multiplicité des petits producteurs, on peut en déduire que le palmier à huile concerne une frange importante de la population.

La Figure 5 présente le groupe 1 constitué de palmeraies appartenant pour la plupart aux grands producteurs. Ces palmeraies sont proches des usines de transformation ou gardées par des agents de sécurité puisqu'elles bénéficient d'apport de sous-produits de transformation des régimes et subissent moins la pression de la population pour l'exportation des feuilles d'élagage. De plus, les propriétaires de ces palmeraies ont été sensibilisés à l'application des engrais, puisqu'ils appliquent les doses recommandées. En effet, leur statut de grands producteurs signifie qu'ils ont les moyens financiers pour acheter les engrais spécifiques au palmier à huile et se sont informés des doses recommandées. Ces types de producteurs ont également un accès facile à une main-d'œuvre qualifiée et recrutent souvent des techniciens agricoles pour la conduite de leurs exploitations. Bien que représentant $13 \%$ des palmeraies sur terre de barre, les palmeraies du groupe 1 occupent près de la moitié de la superficie plantée (Tableau 6). Ceci témoigne du fait que les moyens financiers des grands producteurs leur permettent d'acheter les terrains en jachère ou les forêts secondaires pour l'extension des palmeraies. Ces producteurs contribuent davantage à la déforestation, par l'installation des palmeraies à la place des forêts secondaires, avec toutes les conséquences environnementales qui en découlent : augmentation des gaz à effet de serre, perte de la biodiversité... (Germer et Sauerborn, 2008; Morel et al., 2011).
Les petits producteurs (groupe 2 de la Figure 5) qui disposent d'un faible revenu ont un accès limité aux fumures et à la maind'œuvre qualifiée. Ils se retrouvent également dans le groupe 3 (Figure 5) où les fumures recommandées sont appliquées de façon irrégulière faute de moyens financiers.

L'existence de ces quatre groupes permet d'opérer des choix de palmeraies villageoises pour des études sur les terres de barres du département.

Les différentes modalités de gestion des feuilles d'élagage sont également rencontrées dans les palmeraies sur terres de barre. A tous les âges de plantation à partir de 7 ans, les feuilles d'élagage sont plus exportées qu'elles ne sont restituées (Figure 6). La dominance des palmeraies de type "exportation des feuilles" en phase pré-adulte (7-12 ans) est due au fait que ces palmeraies appartiennent aux petits producteurs (groupe 2 de la Figure 5) et sont situées à proximité des habitations ; ce qui augmente le taux de prélèvement des feuilles pour usages domestiques. Les petits producteurs installent leurs palmeraies près des habitations du fait de leur faible niveau de ressources qui ne leur permettent pas, selon Ton et de Haan (1995), d'acquérir des terrains en jachère, ni des parcelles forestières. Ils ont un faible impact sur la dégradation de l'environnement.

La part importante de la restitution des feuilles dans la classe 13-20 ans pourrait s'expliquer par le fait que les grands producteurs y sont plus représentés et que ces exploitants contrôlent mieux le recyclage des feuilles d'élagage.

\section{Conclusion}

Au terme de cette étude, on retient que la typologie des palmeraies villageoises du département du Plateau, peut se baser sur :

(i) des caractéristiques peu variables : la densité de plantation, le précédent cultural des palmeraies, l'association quasi systématique des cultures vivrières au jeune âge de plantation, avec des variations dans le choix du type de cultures associées, et les pratiques de fertilisation qui sont mal ou peu 
respectées en particulier chez les petits planteurs.

(ii) des caractéristiques variables : la restitution des sous-produits de transformation qui est surtout limitée à quelques grands planteurs et les modes de recyclage des feuilles d'élagage. A partir de 7 ans, les feuilles d'élagage sont plus fréquemment exportées chez les petits producteurs qu'elles ne sont restituées.

Ces caractéristiques provenant des facteurs aussi bien socio-économiques qu'agronomiques permettent d'accepter notre hypothèse de recherche. Elles posent par ailleurs la question de l'adéquation de la nutrition minérale des palmeraies et celle du maintien des stocks de matière organique dans les sols. Elles nous interrogent sur les performances à long terme des palmeraies villageoises au Bénin et font appel à des actions de recherche et développement qui doivent être plus orientées vers les petits et moyens producteurs et impliquer des acteurs d'autres disciplines (agronomie, environnement, foresterie, sociologie...).

L'existence sur les terres de barre de groupes de palmeraies caractérisées par différentes pratiques culturales donne les premières pistes de recherche et facilite le choix des palmeraies pour des actions futures. Cette typologie peut aider au choix de situations représentatives pour approfondir l'étude des stocks de carbone dans le sol en fonction des modes de gestion de la biomasse des palmeraies.

\section{REMERCIEMENTS}

Les auteurs tiennent à remercier les différentes institutions impliquées dans la réalisation de ce travail pour leurs appuis matériels et financiers. Il s'agit particulièrement du Centre de Recherches Agricoles sur les Plantes Pérennes de l'Institut de Recherches Agricoles du Bénin (CRA-PPPobè/INRAB), et de la société PalmElit, filiale du Cirad à Montpellier en France. Ce travail a été également soutenu par le projet RIME-PAMPA ( ${ }^{\circ}$ CZZ 3076), financé par l'AFD (Agence Française de Développement), le MAE (Ministère Français des Affaires Etrangères) et le FFEM (Fond Français pour l'Environnement Mondial), et par la Casa réseau « carbone des sols pour une agriculture durable en Afrique » financé par le MAE et AIRD. Les remerciements vont également à l'endroit de Mr Kossou Fabrice Gilles, Géomètre-expert à l'Institut Géographique National du Bénin, pour ses appuis aux traitements cartographiques. Nous remercions également tous les producteurs de palmier à huile sélectionné du département du Plateau et en particulier les producteurs membres des différentes organisations paysannes (Coopérative Villageoise des Producteurs de Palmier à Huile, Union Communale des Producteurs de Palmier à Huile et Union Régionale des Producteurs de Palmier à Huile) pour leur forte participation à cette étude.

\section{REFERENCES}

Adjadi E. 2008. Le développement du palmier à huile sélectionné au Bénin. Rapport d'étude, CRAPP/Pobè, p. 9.

Adjadi E. 2012. Le développement du palmier à huile sélectionné au Bénin. Rapport d'étude, Actualisation des superficies plantées, CRAPP/Pobè, p. 9.

Adjé AI, Adjadi E. 2001. Diffusion du matériel végétal amélioré palmier à huile en milieu villageois : l'expérience du Bénin. Oléagineux Corps Gras et Lipides, 8(5): 529-533.

Agossou V. 1983. Les sols béninois et leurs potentialités agricoles. Document de colloque: Premières journées de la science et de la technologie, PNUD/FAO, Cotonou, p. 10.

Aholoukpè H, Dubos B, Flori A, Deleporte $\mathrm{P}$, Amadji G, Chotte JL, Blavet D. 2013. Estimating aboveground biomass of oil palm: Allometric equations for estimating frond biomass. Forest Ecology and Management, 292: 122-129.

Ahoyo NR. 2008. Potentialités des filières Anacarde et Palmier à huile au Bénin. Rapport d'étude, SNV-Bénin, p. 81. 
Amadji GL, Aholoukpè HNS. 2008. Impact du niébé (Vigna unguiculata) et de la fumure minérale sur les propriétés chimiques de la terre de barre du Bénin. Etude et Gestion des Sols, 15(3): 147-160.

Arbelot B, Foucher H, Dayon JF, Missohou A. 1997. Typologie des aviculteurs dans la zone du Cap-Vert au Sénégal. Élev. Méd. Vét. Pays Trop., 50(1): 75-83.

Azontondé HA. 1991. Propriétés physiques et hydrauliques des sols au Bénin. Soil Water. Balance in the Sudano-Sahelian Zone. Proceedings of the Niamey Work Shop. February 1991. IA HS Publ., 199: 253-256.

Barthe B, Azontonde A, Blanchart E, Girardin C, Villenave C, Lesaint S, Oliver R, Feller C. 2004. Effect of a legume cover crop (Mucuna pruriens var. utilis) on soil carbon in an Ultisol under maize cultivation in southern Benin. Soil Use and Management, 20: 231-239.

CENATEL (Centre National de Télédétection). 2009. Projet d'Appui au Développement Rural de l'Ouémé-Plateau (PADRO). Carte d'occupation du sol de l'Ouémé-Plateau à 1/200000 : feuille 1,2 et 3 .

Chaléard JL. 2002. La place des cultures vivrières dans les systèmes de production en agriculture de plantation : le cas du département d'Agboville (Côte d'ivoire). Cah. Sci. Hum., 24(1): 35-49.

Corley RHV, Tinker PB. 2003. The Oil Palm $\left(4^{\text {th }}\right.$ edn). Wiley-Blackwell, World Agriculture : UK; 592.

CBD (Convention sur la Biodiversité). 2001. Deuxième rapport annuel, Ministère de l'Environnement et de l'Urbanisme, Bénin, p. 93.

Dagnelie P. 1998. Statistique Théorique et Appliquée (Tome 1). Statistique Descriptive et Bases de l'Inférence Statistique. De Boeck: Bruxelles; 511.

Deans JD, Diagne O, Lindley DK, Dione M, Parkinson JA. 1999. Nutirent andorganicmatter accumulation in Acacia senegal fellow over 18 years. Forest Ecology and Management, 124: 153-167.
Djegui N. 1992. Matière organique et azote dans les sols cultivés sur terres de barre (Bénin). Thèse de doctorat, Ecole Nationale Supérieure d'Agronomie de Toulouse, France, p. 208.

Djegui N. 1995. Les stocks organiques dans les sols cultivés sous palmeraie et cultures vivrières dans le sud du Bénin. Actes de séminaires: Fertlité du milieu et stratégies paysannes sous les tropiques humides. CIRAD, 189 - 193.

Djegui N, Daniel C. 1996. Le développement du palmier à huile au Bénin : une approche spécifique. Oléagineux Corps Gras et Lipides, 3(2): 125-130.

Elong GJ. 1983. Les plantations villageoises de palmier à huile de la Socapalm dans le bas- Moungo (Cameroun) : un projet mal integré aux préoccupations des paysans. Les Cahiers d'Outre-Mer, 224: 11.

Dufumier M, Labrousse R, Losch B. 1997. Les plantations des zones tropicales humides : caractéristiques et perspectives. Plantation Recherche Développement, 4(2): 81-90.

Follin JC. 2000. Enjeux de la recherche sur le palmier à huile en Afrique. Oléagineux Corps Gras et Lipides, 7(2): 138-139.

Fournier S, Okounlola-Biaou A, Adjé AI. 2001. L'importance des filières locales: le cas de l'huile de palme au Bénin. Oléagineux Corps Gras et Lipides, 8(6): 646-653.

Fournier S, Muchnik J, Requier-Desjardins D. 2002. Enjeux et contraintes du développement de la filière huile de palme au Bénin : une approche par les systèmes agro-alimentaires localisés. Les Cahiers d'Outre-Mer, 220: 475-494.

Germer J, Sauerborn J. 2008. Estimation of the impact of oil palm plantation establishment on greenhouse gas balance. Environ. Dev. Sustain., 10: 697-716.

IGN (Institut Géographique National - Paris). 1968. Carte Régulière de l'Afrique de l'Ouest à 1/200000. Carte topographique, République du Dahomey, feuille PortoNovo, NB - $31-\mathrm{XV}$, Institut Géographique National - Paris. 
Juhé-Beaulaton D. 1998. La Palmeraie du Sud Bénin avant la Colonisation : Essai d'Analyse Historique. In Plantes et Paysages d'Afrique. Une Histoire à Explorer. Chastanet M (ed) KarthalaCRA: Paris ; 327-352.

Kossoumna Liba'a N, Havard M. 2006. Mutations de la filière cotonnière dans les provinces septentrionales du Cameroun. Perception et stratégies paysannes. Cahiers de Géographie du Québec, 50(139): 65-82.

MAEP (Ministère de l'Agriculture de l'Elevage et de la Pêche). 2009. Plan stratégique de relance du secteur agricole, Cotonou, MAEP.

Mbetid-Bessane E, Havard M, Djamen NP, Djonnewa A, Djondang K, Leroy J. 2002. Typologies des exploitations agricoles dans les savanes d'Afrique centrale. Actes du colloque, 27-31 mai 2002, Garoua, Cameroun, p. 10.

Morel AC, Saatchi SS, Malhi Y, Berry NJ, Banin L, Burslem D, Nilus R, Ong RC. 2011. Estimating aboveground biomass in forest and oil palm plantation in Sabah. Malaysian Borneo using ALOS PALSAR data. Forest Ecology and Management, 262: 1786-1798.

Nouy B, Baudouin L, Djégui N, Omoré A. 1999. Le palmier à huile en conditions hydriques limitantes. Plantation Recherche Développement, 6(1): 31-45.

Perrot C, Landais E. 1993. Exploitations agricoles : pourquoi poursuivre la recherche sur les méthodes typologiques? Dossier : méthodes d'études en milieu paysan. Cah. Rech. Dév., 33: 13-23.

Quantum GIS Development Team. 2013. Quantum GIS Geographic Information System. Open Source Geospatial Foundation Project. http://qgis.osgeo.org

Rafflegeau S. 2008. Dynamique d'implantation et conduite technique des plantations villageoises de palmier à huile au Cameroun : Facteurs limitants et raisons des pratiques. Thèse de doctorat, Institut des Sciences et Industries du Vivant et de l'Environnement, Agro Paris Tech, France, p. 148.

SNV-Bénin. 2009. Potentialités des filières anacarde et palmier à huile au Benin. Rapport d'études, Dutch Development Organisation (SNV), Bénin, p. 34.

Smith OB, Moustier P, Mougeot LJA, Fall A. 2004. Développement Durable de l'Agriculture Urbaine en Afrique Francophone: Enjeux, Concepts et Méthodes. Centre de coopération internationale en recherche agronomique pour le développement (CIRAD) et Centre de recherches pour le développement international (CRDI) : Ottawa; 173.

Ton P, de Haan LJ. 1995. A la Recherche de l'Agriculture Durable au Bénin, Cortie C, Beenakker J, Dietz T, Thissen F, van Bruinessen A (eds). Institut voor Sociale Geografie : van Amsterdam; 209.

Volkoff B, Willaine P. 1976. Carte Pédologique de Reconnaissance de la République Populaire du Bénin. Feuille de Porto-Novo. Notice Explicative $\mathrm{n}^{\circ} 66$ (1), ORSTOM : Paris; 39.

Volkoff B. 1976a. Carte Pédologique de Reconnaissance de la République Populaire du Bénin au 1 /200000. Feuille d'Abomey. Note Explicative $n^{\circ} 66$ (2), ORSTOM : Paris ; p. 40.

Volkoff B. 1976b. Carte Pédologique de Reconnaissance de la République Populaire du Bénin au 1 /200000. Feuilles Abomey et Porto-Novo. ORSTOM : Paris. 